\title{
El impacto del bullying en el desarrollo integral y aprendizaje desde la perspectiva de los niños y niñas en edad preescolar y escolar
}

\author{
The Impact of Bullying in the Integral Development and Learning from the Perspective of \\ Children in Preschool and School
}

\section{O impacto do bullying na aprendizagem e no desenvolvimento integral a partir da perspectiva das crianças na pré-escola e na escola}

María Ester Morales-Ramírez ${ }^{1}$

Universidad Nacional

Instituto de Estudios Interdisciplinarios de la Niñez y la Adolescencia

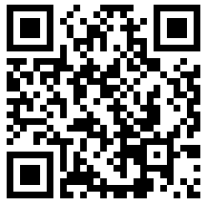

Heredia, Costa Rica

mmorales@una.cr

http://orcid.org/0000-0003-1088-1895

Margarita Villalobos-Cordero²

Universidad Nacional

Instituto de Estudios Interdisciplinarios de la Niñez y la Adolescencia

Heredia, Costa Rica

villalobos.margarita@gmail.com

http://orcid.org/0000-0003-4183-3757

Recibido 12 de abril de 2016 • Corregido 26 de mayo de 2017 • Aceptado 17 de julio de 2017

Received 2 de abril de 2016 • Revised 26 de mayo de 2017 • Accepted 17 de julio de 2017

Recebido 2 de abril de 2016 • Revisado 26 de mayo de 2017 • Aprovado 17 de julio de 2017

\footnotetext{
${ }^{1}$ Doctora en Educación. Maestría en Psicología Industrial y Organizacional. Licenciada en Psicología. Investigadora y extensionista en el INEINA, CIDE de la Universidad Nacional de Costa Rica.

${ }^{2}$ Maestría en Psicología. Licenciada en Psicología. Investigadora y extensionista en el INEINA, CIDE de la Universidad Nacional de Costa Rica.
} 
doi: http://dx.doi.org/10.15359/ree.21-3.2

URL: http://www.una.ac.cr/educare

CORREO: educare@una.cr

Resumen: El artículo que a continuación se presenta forma parte de una investigación más amplia acerca del impacto del bullying en el desarrollo integral y aprendizaje de los niños y niñas en edad preescolar y escolar. Se esbozó un objetivo que permitiera "analizar el impacto del bullying o acoso escolar en el desarrollo integral de los niños y niñas en edad preescolar y escolar para promover estrategias de prevención e intervención en esta problemática". Para lograrlo, se realizó un estudio con enfoque mixto, de tipo exploratorio y descriptivo de la influencia que ejerce en el aprendizaje y desarrollo de una persona menor de edad la vivencia del acoso. La información contenida en el artículo da cuenta únicamente de las respuestas que se refieren al impacto y que fueron aportadas por 857 niños y niñas, a saber: 237 de preescolar, 286 de III grado y 334 de VI grado. Se trabajó con estos grupos con el fin de poder detectar si desde preescolar había indicios de acoso y si existía alguna diferencia significativa en la percepción que de esta problemática tenía el estudiantado del I y III ciclo. Se trabajó con 14 escuelas de la provincia de Heredia, Costa Rica, seleccionadas al azar y previa coordinación con las autoridades y figuras parentales para la obtención del correspondiente aval. Para recopilar la información se construyó un cuestionario conformado por preguntas abiertas y cerradas de respuesta sí y no, y a la niñez del nivel preescolar se les realizó una entrevista semiestructurada y basada en el cuestionario diseñado. El análisis de los datos se hizo desde una perspectiva cuantitativa y cualitativa, la que incluye categorías emergentes elaboradas a partir de las respuestas aportadas por los niños y las niñas, con el objetivo de que su sentir y pensar ante esta problemática se constituya en insumo para que todos y todas logremos concienciarnos acerca de la imperante necesidad de prevenirla y abordarla en todos los ámbitos en los que nos desenvolvemos. Entre los resultados más relevantes encontrados, se tiene que 229 estudiantes (26.7\%) indicaron estar siendo objeto de acoso, de esta cantidad, 198 (86.5\%) efectivamente están sufriendo bullying, ya que el tiempo de recibirlo va de semanas a un año y con episodios replicados en un mismo día. Asimismo, el mayor impacto de esta problemática ha sido en el área socioemocional, seguido de una incidencia en el aprendizaje, principalmente en la motivación, en razón de que el 29.2\% manifestó abiertamente su deseo de no continuar asistiendo al centro educativo. Los lugares donde las personas estudiantes fueron víctimas de acoso son el aula, el recreo, los pasillos, fuera de la escuela, el comedor y los servicios sanitarios. En opinión de las investigadoras, es imperativa la necesidad de que en el centro educativo se realice un diagnóstico, con toda la población estudiantil, que permita determinar la incidencia real de esta problemática, una supervisión constante del personal docente del estudiantado de su responsabilidad y una capacitación de toda la comunidad educativa, con miras no solamente a concienciarles y sensibilizarles, sino también para poder abordar el acoso oportuna y eficazmente en el marco de la normativa existente.

Palabras claves: Bullying o acoso escolar; niñez; efectos.

Abstract: This article is part of a wider investigation about the impact of bullying on the integral development and learning of preschoolers and schoolchildren. An objective was designed to allow "analyzing the impact of bullying in the integral development of preschool and schoolchildren to promote prevention and intervention strategies to address this problem."To achieve this, a study with a mixed approach, of exploratory and descriptive nature, was conducted to analyze the influence exerted in the learning and development of a child who experienced bullying. The information contained in the article only renders the answers related to the impact and provided by 857 children, namely: 237 preschoolers, 286 of the third grade and 334 of the fourth grade. We worked with these groups in order to detect if there were signs of bullying from preschool, and if there was any significant difference in the perception of this problem from students of the first and third cycle. We worked with 
14 schools in the province of Heredia, Costa Rica, randomly selected, and coordinated with authorities and parents to obtain authorizations. To compile the information, a questionnaire was constructed, consisting of open and closed questions of yes and no answer. Also a semi-structured interview based on the designed questionnaire was applied to the children at the preschool level. The data were analyzed from a quantitative and qualitative perspective. This perspective included emerging categories elaborated from the answers provided by the children, to assure that their feelings and thoughts about bullying constitute an input to raise awareness of the prevailing need to prevent this problem and to address it in all the areas in which it is present. Among the most relevant results found, 229 students (26.7\%) reported having been harassed; of these, $198(86.5 \%)$ are actually suffering from bullying, since the time for suffering this harassment can vary from weeks to a year, with repeated episodes in a single day. Likewise, the greatest impact of this problem has been in the socio-emotional area, followed by an incidence in learning, mainly in motivation, because $29.2 \%$ openly expressed that they did not want to continue attending the school. The places for bullying against students are classrooms, hallways, school cafeterias, restrooms, out of school facilities, and during recess. In the opinion of the researchers, it is imperative that the educational center conducts a diagnosis with the entire student population allowing to determine the real incidence of this problem, to establish a constant supervision of the teaching staff with students under their responsibility, and to train the whole educational community, not only to raise awareness, but also to address bullying in a timely and effective manner within the existing legislation framework.

Keywords: Bullying; childhood; effects.

Resumo: $\mathrm{O}$ artigo apresentado a seguir é parte de uma investigação mais ampla sobre o impacto do assédio moral no desenvolvimento integral e aprendizagem das crianças na pré-escola e escola. Desenhou-se um objetivo que permitiria "analisar o impacto do bullying ou assédio no desenvolvimento integral de crianças em pré-escolar e escola para promover estratégias de prevenção e intervenção sobre esta questão". Para alcançar este objetivo, foi feito um estudo com abordagem misto, exploratório e descritivo da influência do assedio na aprendizagem e desenvolvimento das crianças. As informações dessa pesquisa tomam em conta apenas as respostas que se relacionam com o impacto e foram proporcionadas por 857 crianças: 237 em pré-escolar, 286 de 3a série e 334 de $4^{\text {a }}$ série. $\mathrm{O}$ trabalho feito com esses grupos teve a finalidade de detectar se desde o pré-escolar já existia sinais de assédio e se havia alguma diferença significativa na percepção deste problema nos estudantes de primaria. Participaram dessa pesquisa 14 escolas na província de Heredia, Costa Rica, selecionados aleatoriamente, e com a coordenação das autoridades e figuras parentais para obter a garantia correspondente. As informações foram conseguidas através de um questionário composto por perguntas abertas e fechadas, com resposta de sim ou não, e para as crianças que estavam em préescolar também foi feita uma entrevista semiestruturada e com base no questionário anteriormente mencionado. A análise dos dados foi feito a partir de uma perspectiva quantitativa e qualitativa, incluindo as categorias emergentes extraídas das respostas dadas pelas crianças, a fim de que sua forma de sentir e pensar fossem tomados em conta para conscientizar sobre a necessidade urgente de prevenir e tratar o problema do bullying em todas as áreas em que atuamos. Entre os resultados mais relevantes, encontramos 229 estudantes (26,7\%) que afirmaram ser vitimas de assédio, desses, 198 $(86,5 \%)$ estão realmente sofrendo bullying diariamente e de forma repetitivo, que vão desde semanas a um ano completo. Além disso, o maior impacto deste problema é na área sócio emocional, seguido 
doi: http://dx.doi.org/10.15359/ree.21-3.2

URL: http://www.una.ac.cr/educare

CORREO: educare@una.cr

\begin{abstract}
pelo impacto na aprendizagem, principalmente na motivação, aonde 29,2\% expressaram abertamente seu desejo de não frequentar mais a escola. Os lugares onde as crianças foram vitimas de assédio são a sala de aula, o recreio, os corredores, fora da escola, no refeitório e nos banheiros. De acordo com os pesquisadores, o centro educativo deveria ser responsável por realizar um diagnóstico com toda a população estudantil, para determinar a incidência real deste problema. Também é necessária uma supervisão constante sobre a responsabilidade dos professores e proporcionar formação sobre o tema com toda comunidade educativa, com o objetivo de não somente de conscientizar e sensibilizar, como também prevenir o assédio de forma antecipada e eficaz no âmbito da legislação em vigor.
\end{abstract}

Palavras chaves: Bullying ou intimidação; infância; efeitos.

\title{
Introducción
}

El aumento de la violencia y las conductas agresivas tendientes a la destructividad humana ha ido alcanzando niveles insospechados en el presente siglo en el ámbito internacional y Costa Rica no ha sido la excepción. Esta se ha constituido en una de las problemáticas más complicadas de resolver, en la medida que promueve la instauración de una cultura basada en la violencia que incide negativamente en todos los actores involucrados, en tanto la reiterada exposición a la violencia conlleva a la habituación y al riesgo de considerarla normal o aún peor, inevitable. Esto es consecuente con lo planteado por Castro y Reta (2013), en cuanto a que "como enfermedad social, la violencia contagia, se extiende, se oculta, muta y continúa desafiándonos" (p. 12).

En este contexto, las personas menores no están exentas de convertirse en víctimas de actos violentos, tanto así que, como bien señala Pinheiro $(2006$, p. 3) en el Informe mundial sobre la violencia contra los niños y niñas, "la variedad y el alcance de todas las formas de violencia contra los niños y las niñas apenas ahora se están haciendo visibles, así como la evidencia del daño que hacen", en su aprendizaje y desarrollo integral para toda la vida.

En los últimos años resulta de especial importancia el incremento de situaciones conflictivas en nuestra sociedad costarricense, vivenciándose estas en los diferentes contextos en los que se desarrolla la población infantil, tales como la familia, las instituciones creadas para protegerla, los lugares donde se labora, la comunidad y los centros educativos, ya sea de preescolar, primaria o secundaria y, más específicamente, el aula escolar, espacio en el que no pueden obviarse las experiencias conflictivas que se presentan entre los diferentes actores de la comunidad educativa.

Si bien, todo acto de violencia es injustificable en cualquier ámbito en el que las personas menores de edad se desenvuelvan, más intolerable se torna esta práctica en los centros educativos, sobre todo porque son esos los espacios en los cuales permanecen la mayor cantidad de horas durante el día, lo que sin duda alguna es una violación del derecho que tienen a una convivencia pacífica. En relación con lo anterior, Castro y Reta (2013) sugieren que no estamos tomando las mejores decisiones y lo fundamentan en el hecho de que los niveles de violencia presentes en los centros educativos superan nuestras expectativas. Al respecto

4

María Ester Morales-Ramírez y Margarita Villalobos-Cordero

Los artículos de la Revista Electrónica Educare del Centro de Investigación y Docencia en Educación de la Universidad Nacional, Costa Rica, se comparten bajo términos de la Licencia Creative Commons: Reconocimiento, № Comercial, Sin Obra Derivada 3.0 Costa Rica. Las autorizaciones adicionales a las aquí delimitadas se pueden obtener en el correo: educare@una.cr 
Pinheiro (2006) menciona que la realidad es que el entorno educativo expone a la población infantil a actos violentos, castrando con ello el disfrute de los derechos que les compete, incluido el de la educación. Agrega que es por esta razón que "los adultos que supervisan, administran y trabajan en estos lugares tienen el deber de proporcionarles entornos seguros y acogedores que apoyen y promuevan su educación y desarrollo" (p. 111).

En el entorno educativo, últimamente se utiliza el término bullying o acoso escolar para referirse al maltrato que reiteradamente se ha venido presentando entre pares, por lo que incumbe examinar las interacciones que se establecen entre la población docente y el estudiantado y de estos grupos entre sí, tanto como los vínculos entre las figuras parentales y su prole y que previenen o favorecen las conductas de acoso.

En opinión de Beane (2006), el bullying se aprende y se desaprende, de ahí la urgencia de ayudar al estudiantado para que ponga en práctica acciones más positivas que a todas luces tendrán un mejor impacto, que el etiquetarles o humillarles cuando acosan o son objeto de acoso.

Si bien en Costa Rica el aumento de la violencia en los centros educativos en comparación con otros países es menor, sí es claro que cada vez se detectan mayores manifestaciones preocupantes como consecuencia de la crisis familiar, cultural y social que enfrenta el país, con su consiguiente efecto en la niñez.

Es por esto y por lo que plantea Beane (2006, p. 12) en cuanto a que "a la escuela vamos a desarrollarnos íntegramente como personas en todos los aspectos: cognitivos, afectivos, emocionales y morales", que surgió la inquietud de realizar un estudio que permitiera conocer la opinión que tienen los niños y las niñas en relación con la prevalencia del acoso escolar en los centros educativos a los que asisten, así como del impacto que este tiene en el desarrollo integral y aprendizaje de quienes lo sufren.

\section{Marco teórico}

\section{Concepto de bullying}

El término inglés bullying es conocido también como hostigamiento, acoso escolar, o bien, matonaje escolar. La palabra "bully" es empleada para denominar a la persona que acosa a sus pares mediante su conducta.

Beane (2006) destaca que para poder hacer frente al problema del acoso escolar como manifestación dañina de la agresividad, es fundamental asumir que estamos ante un comportamiento, una actitud o una relación, que si bien tienen una base agresiva, "no se puede confundir con otros comportamientos, actitudes y relaciones que, aunque igualmente tengan un cierto componente agresivo, no son idénticas" (p. 11), de ahí la necesidad de conocer los rasgos que permiten diferenciarlo de otras conductas violentas. 
doi: http://dx.doi.org/10.15359/ree.21-3.2

URL: http://www.una.ac.cr/educare

CORREO: educare@una.cr

Al respecto Beane (2006, pp. 11-12) exterioriza que el acoso escolar es:

Un fenómeno de abuso, malos tratos, hostigamientos o exclusión social que, cuando aparece, contamina el clima de relaciones interpersonales, produce sensación de malestar y termina afectando a las personas y a las actividades que las personas tienen que realizar juntas.

Educarchile (2009) hace referencia a que en materia de acoso escolar se impone la cultura del silencio, la que impide que las personas adultas sepan qué estudiante está siendo víctima de bullying. A los sujetos agresores les beneficia ante la autoridad $u$ otra persona adulta dispuesta a intervenir, y en el grupo de pares la ley se invierte porque le interesa que cada acto agresivo sea publicado para obtener el reconocimiento que busca. Por esto es importante, como lo cita Rojas (2005), desarrollar en las personas una cultura de la denuncia ante la amenaza del silencio cómplice cuando se presenta un comportamiento de acoso escolar.

Fuensanta (2012) lo percibe de la siguiente manera:

Forma de maltrato, intencionado, perjudicial y persistente de un estudiante, o grupo de estudiantes, hacia otro compañero, generalmente más débil, al que convierten en su víctima habitual. ... Se trata de una conducta agresiva persistente, de manera que, ... un alumno o grupos de alumnos ha establecido una relación de intimidación con otro. (p. 25)

\section{Características del bullying}

Las siguientes características deben tomarse en cuenta a efecto de poder discriminar entre el bullying y un episodio de agresión o violencia que se presente entre estudiantes:

- Existe una desigualdad de las condiciones psicológicas entre sus participantes (Voors, 2005, citado por Cobo y Tello, 2013).

- Cobo y Tello (2013) hacen referencia a que se presenta sin provocación previa de la víctima y de manera recurrente durante semanas, meses o incluso años; los ataques son físicos, verbales o psicológicos, con el propósito de ocasionar miedo, dolor o daño a la víctima, y existe un abuso de poder del más fuerte al más débil validado por el silencio de sus participantes.

- Las medidas preventivas se presentan cuando la dinámica de la agresión-victimización está muy arraigada, es decir, la víctima está tan indefensa que no "puede hacer nada para cambiar la situación, y el acosador ha consolidado un amplio repertorio de conductas agresivas" (Fuensanta, 2012, p. 25). 


\section{Tipos de bullying}

Estudios consultados como el de Rojas (2005), Sanmartín (2006, citado por Convivencia Escolar, 2011), Oñederra (2008); Cerezo (2004, citado por el Ministerio de Educación Pública, 2012); Narváez y Salazar (2012); Cobo y Tello (2013) y Castro y Reta (2013) coinciden al anotar que los tipos de bullying y sus manifestaciones son las que seguidamente se presentan:

El bullying físico: Puede ser directo o indirecto y detectarse con más facilidad, ya que la mayoría de las veces deja huellas en la víctima por las lesiones físicas que podría ocasionar en el cuerpo o en las pertenencias. Se manifiesta mediante golpes, patadas, empujones, zancadillas, encerrar a la víctima, maltratar, dar puñetazos, poner el pie encima, escupir, agredir con objetos, amenazar, arañar, morder, pellizcar, impedir que vaya al baño, al patio o que circule o juegue en un determinado espacio.

El bullying verbal: Es el que con más frecuencia se presenta entre las "mujeres de todas las edades, sin que por ello pueda considerarse que es exclusivo de este género" (Harris y Petrie, consultados por Cobo y Tello, 2013, p. 23). Se caracteriza por actos violentos a través de la palabra, insultos, sobrenombres descalificativos y despectivos, humillaciones, burlas crueles, ridiculizaciones, resaltar los problemas físicos, las diferencias sociales, menosprecio en público, amenazas, hablar mal de alguien, sarcasmos, dedicar canciones, calumnias, injurias o rumores falsos, algunos de los cuales se han realizado empleando el teléfono celular.

El bullying social: Procura aislar a la víctima del resto del grupo, acción que se consigue debido a la actitud pasiva que muestran sus participantes. Se evidencia mediante la indiferencia, aislamiento, rumores maliciosos y malintencionados que alejan a las amistades, la exclusión de la víctima en actividades, las manipulaciones de las relaciones de amistad, y el desprestigio.

El bullying gesticular: Difícil de detectar y de denunciar, ya que según Cobo y Tello (2013), si bien ocurre en presencia de una persona adulta, esta no ayuda porque no mira lo que ocurre, conllevando a que la víctima se sienta más vulnerable e imposibilitada para actuar.

El bullying sexual: Se maltrata a la víctima haciendo referencia a las partes íntimas de su cuerpo, se acosa con actos o comentarios, se toca distraídamente y se niega la acción o se le presiona para que haga algo que no quiere (Castro y Reta, 2013).

El bullying entre hermanos o hermanas: Se desacredita o miente sobre cosas o actos que hace algún hermano o alguna hermana. Se utilizan pellizcos, zapear, motes, golpes o empujones, entre otros.

El bullying homófobo: Se maltrata por la orientación sexual de la víctima, sea esta real o imaginaria.

El bullying racista: Se maltrata a la víctima haciéndole bromas crueles, difusión de rumores humillantes, entre otros, por el origen étnico (MEP, 2012). 
doi: http://dx.doi.org/10.15359/ree.21-3.2

URL: http://www.una.ac.cr/educare

CORREO: educare@una.cr

El bullying económico o patrimonial: Se le exige a la víctima que entregue el dinero, la merienda o las cosas que lleva al centro educativo. De igual manera el sujeto acosador podría robar, perder, esconder o destruir las pertenencias de la víctima.

El cyberbullying: Es el acoso o matonismo que se da a través de los medios electrónicos como internet, las redes sociales o los teléfonos celulares, y puede incorporar el maltrato verbal, psicológico, el social y el visual (MEP, 2012). Es un acto de crueldad encubierta, tanto así que la característica más nociva de este tipo de bullying es que es anónimo.

El bullying psicológico: De acuerdo con Dot (1988) y Cerezo, 2004 (citados por el Ministerio de Educación Pública, 2012), este tipo de bullying es un componente muy sutil que transversa todas las formas de acoso escolar antes mencionadas. Las acciones $u$ omisiones van tendientes a dañar la estabilidad psicológica de la víctima, a afectar su autoestima y a fortalecerle la sensación de inseguridad y temor.

\section{Personas involucradas en el acoso escolar}

Calvo, Cerezo y Sánchez (2004, citados por el MEP, 2012) plantean que, en la problemática del acoso e intimidación en el centro educativo, se consideran tres componentes que interactúan:

- La víctima, que tiene diversas características que la colocan en la posición de dominada.

- La persona agresora que hace evidente el deseo de dominar.

- El centro educativo cuyas condiciones favorecen, toleran y permiten que un estudiante o una estudiante o grupo se manifieste agresivamente contra otra persona, mientras que el resto son los sujetos testigos, que observan con complicidad o con evidente pasividad.

\section{Desarrollo moral y bullying}

El tema del bullying, desde el punto de vista disciplinario, es un asunto concerniente al desarrollo moral del niño o la niña. Sin embargo, no se puede dejar de pensar en lo que se ha considerado aceptable o no desde la moralidad, especialmente, cuando analizamos el tema de aquellas conductas consideradas positivas o negativas, de ahí la necesidad de diferenciar entre una conducta agresiva y el comportamiento que debe ser catalogado como bullying, pues ello determinará, no solo el efecto en la persona, sino el abordaje que se le dé al caso.

Castro y Reta (2013) aluden a que la agresividad desde siempre ha sido una conducta adaptativa inherente al ser humano y primordial para la evolución de la especie. No obstante, agregan que históricamente estos comportamientos agresivos han variado esa razón de ser, dando lugar a conductas tendientes al sometimiento de unos sobre otros con el fin de "llevar a cabo destrucciones masivas" (p. 25).

8 
Spinoza, comentado por Baier (1993), percibe la crueldad como el hacer maldades a quienes se ama o a quienes solo han querido el bien para la persona que presenta conductas de crueldad. Por tanto, quedaría por fuera la conducta de castigo, revancha o venganza con la cual podría responder la víctima a nivel individual o social. Así las cosas, se puede partir, entonces, de que existe una normativa que nos estipula cuáles son las conductas sociales incorrectas, estas últimas sujetas a castigos aceptados socialmente.

Al respecto Florian (2003) refiere que la insatisfacción de las necesidades básicas en un niño o una niña podría hacerle experimentar frustraciones a temprana edad, especialmente cuando la madre es depresiva o violenta, llevándole a visualizar el mundo indiferente a sus necesidades y, por consiguiente, a experimentar odio y violencia por el displacer que siente ante el intercambio con el otro ser. De igual manera, el niño o niña, aprende que sus deseos difieren de los de la autoridad, en la medida en que tiene que aprender a autocontrolarse sometiéndose a las demandas externas e incluso recibiendo castigo. Es aquí, en opinión de la autora, donde se originan los vínculos sadomasoquistas, por lo que el placer se asocia con el sufrimiento en este vínculo primario.

Desde la perspectiva de Baier (1993), queda en evidencia que un comportamiento cruel puede presentarse a partir de la ira, el enojo o el enfado, lo cual se asocia a una conducta instintiva de naturaleza humana para justificar dicha conducta. Asimismo, se puede visualizar como una conducta vengativa, que tiene como propósito atormentar a la víctima mediante formas crueles para saciar dichos deseos.

\section{Incidencia del bullying en el desarrollo integral}

Blanchard y Muzás (2007) afirman que los factores cognitivos intervienen en el bullying en la medida en que se presentan problemas en la codificación y decodificación de la información que se recibe, de los sentimientos, de los pensamientos e intenciones, tanto como cierta incapacidad para reflexionar sobre el asunto especialmente por un comportamiento impulsivo, producto de la poca tolerancia a la frustración cuando no salen las cosas como se desea.

Castro y Reta (2013) indican que "la agresividad desde el punto de vista fisiológico incluye comportamientos con mínimos efectos negativos en el desarrollo de los niños, adolescentes y de su entorno" (p. 25). Sin embargo, Cid, Díaz, Pérez, Torruella y Valderrama (2008) apuntan que se han observado efectos perennes en el desarrollo de la niñez que vive en hogares violentos, por lo que en el futuro podrían desarrollar pocas habilidades sociales, conductas agresivas y tendencia a ser personas adultas agresoras.

Beane (2006) plantea que el centro educativo promueve el desarrollo psicológico y social, así como el aprendizaje, no obstante, a la vez está presente cierto riesgo, fundamentalmente cuando la dinámica se caracteriza por "enfrentamientos sociales, conflictividad o violencia" (pp. 12-13). 
doi: http://dx.doi.org/10.15359/ree.21-3.2

URL: http://www.una.ac.cr/educare

CORREO: educare@una.cr

Resalta este autor la necesidad de que todos los actores de la comunidad escolar estén concienciados acerca de la influencia que tiene la dinámica que se desarrolle en el centro educativo, en la formación de la personalidad del estudiantado y en la armonía emocional del personal docente.

Según Beane (2006), para que la escuela brinde una adecuada educación afectiva y social debe velar por no convertirse en un ámbito terapéutico, ni tampoco en un espacio donde el estudiantado tenga que aprender a defenderse de los actos violentos del grupo de pares. Pero sí le corresponde instituirse en un espacio público que forma y construye la personalidad individual y social de sus estudiantes y en el cual se fortalecen los vínculos afectivos entre quienes integran la comunidad educativa.

De acuerdo con Castro y Reta (2013), la agresividad se manifiesta intensa y temporalmente en la adolescencia y tiende a disminuir en tanto la intervención del entorno sea positiva y oportuna. De no ser así, cabe la posibilidad de que este comportamiento evolucione hacia otras formas de violencia antisocial y patológica, matizada por maneras hostiles, alienadoras y poco consecuentes con las normas y valores sociales que prevalecen. Estas conductas podrían estar dirigidas a las personas o a los animales "con la intención de causar daño físico o psicológico" (p. 26).

Los estudios precitados denominan a este tipo de violencia como la "maladaptativa, es no regulada o desinhibida"(Castro y Reta, 2013, p. 26), producto de una exagerada reacción al estímulo que la causó o bien a una introyección de conductas agresivas aprendidas en un contexto familiar o comunitario hostil. Agregan que este tipo de violencia podría derivar en trastornos disociales o antisociales y en personalidades psicopáticas, manifestándose la persona no solamente violenta, sino además propensa a depositar en la víctima toda la responsabilidad de lo que le ocurre, al no experimentar sentimientos de culpa y, por consiguiente, no asumir la responsabilidad del acto.

Añaden Castro y Reta (2013) que, en el tema del desarrollo integral, específicamente, los estadios del desarrollo psicoafectivo podrían presentar trastornos como los que se citan a continuación en caso de estar ante un acoso escolar:

- Continuas intrusiones en el desarrollo ocasionando una afectación en la evolución normal de este.

- Los conflictos inherentes a cada etapa del desarrollo podrían verse potenciados con la presión que pueda derivarse del contexto y de no resolverse oportunamente podrían ser interiorizados como conflictos neuróticos.

- Podría presentarse un trastorno derivado de la débil vinculación y de la poca satisfacción de las necesidades emocionales y físicas de la persona menor de edad en etapas tempranas de su desarrollo. 
- El trastorno de tipo inhibido podría presentarse ante los constantes fracasos para establecer y sostener relaciones interpersonales en cada etapa del desarrollo.

- El trastorno de tipo desinhibido podría estar presente en tanto no desarrolla la capacidad para establecer relaciones sociales duraderas y apropiadas.

\section{Consecuencias del bullying en los diferentes actores}

Collell y Escudé (2014) encontraron que el impacto del acoso escolar es grave en todas las personas que participen, es decir, tanto para la víctima, como para quien ejerce el acoso y las demás personas que estén situadas en el entorno en el que se produce, de ahí la importancia de mencionar a continuación algunas de ellas.

\section{En la víctima}

Beane (2006) cita a Ortega para plantear que los episodios de bullying se ponen en práctica mediante formas inhumanas de hostigamiento, intimidación y maltrato, cuyo fin es arruinar la seguridad y el bienestar de las víctimas, aunado al deterioro de la personalidad moral del sujeto agresor, ambas personas en proceso de desarrollo y cuyo daño psicológico podría tener serias repercusiones en la vida adulta

Oñederra (2008) enlista una serie de consecuencias que tiene el acoso en la víctima, las cuales se exponen seguidamente:

- Fracaso escolar, entendido como rechazo a la escuela, exclusión, bajo rendimiento, ausentismo y repitencia.

- Crisis de ansiedad, pánico y depresión.

- Constante sentimiento de culpa.

- Déficit en la autoestima, autoconcepto negativo, autodesprecio, inseguridad.

- Decisiones poco asertivas

- Alteraciones del estado de ánimo, de la conducta, sentimientos de ira.

- Introversión, timidez, aislamiento social, impopularidad, pocas relaciones sociales

- Insatisfacción familiar.

- Poca eficacia en las acciones debido a la desmotivación.

- Síntomas psicosomáticos como insomnio, enuresis y dolores físicos.

- Cambios frecuentes de centro educativo. 
doi: http://dx.doi.org/10.15359/ree.21-3.2

URL: http://www.una.ac.cr/educare

CORREO: educare@una.cr

Por su parte, Arroyave (2012) agrega a lo anterior que ante el aumento de poder de la persona acosadora, la víctima experimenta la ideación suicida, debido a que se siente desamparada frente a la situación, cree que es merecedora de lo que ocurre y que, por consiguiente, no vale la pena estar en un lugar que le ocasiona tanto sufrimiento, sentimiento que se presenta con mayor frecuencia entre las mujeres que en los varones.

Al respecto, Cobo y Tello (2013) son de la opinión de que cuando un niño o niña sufre este tipo de agresión por un tiempo prolongado, podría llegar a tener un daño emocional que da lugar a una permanente sensación de angustia, ansiedad, inseguridad, su autoestima se lesiona ampliamente y tiene dificultad para relacionarse con las demás personas, debido a que son sujeto de burlas por lo que dicen y hacen (Cobo y Tello, 2013).

Olweus (citado por Cobo y Tello, 2013) explica que los pensamientos suicidas y hasta el quitarse la vida acontece cuando la víctima no soporta lo que le sucede y no encuentran otra salida. Cuando la víctima no recibe la ayuda necesaria, en su vida adulta corre "el riesgo de no poder establecer buenas relaciones sociales, y generan patrones disfuncionales e inestables en la familia y el trabajo" (p. 29).

Relacionado con lo anterior, se tiene que Castro y Reta (2013, p. 59) aluden a las repercusiones que a corto y largo plazo se dan en la víctima, a saber:

A corto plazo: se evidencian dificultades para concentrarse, baja autoestima, poca asertividad, dificultades para integrarse, miedo a la escuela, a compañeros y compañeras, docentes y trabajo académico, inestabilidad emocional, mal carácter, absentismo, alteraciones del sueño y enfermedades psicosomáticas.

A mediano plazo: podría mostrar ansiedad, depresión, agresiones a otras personas y comportamiento socialmente conflictivo.

\section{En el sujeto acosador}

La revisión bibliográfica da cuenta de que las repercusiones que tiene el bullying en el sujeto acosador son:

- Dificultades para el cumplimiento de normas, relaciones sociales negativas, déficit en autoconcepto, alta autoestima, falta de empatía y de sentimiento de ira, culpa, crueldad, insensibilidad e irresponsabilidad (Oñederra, 2008).

- Voors, citado por Cobo y Tello (2013) agrega fracaso escolar, rechazo a la escuela, conductas antisociales, adictivas y delictivas, incumplimiento de normas, relaciones sociales negativas, crueldad, depresión e ideación suicida, persistencia de síntomas a largo plazo y en edad adulta. 
- La exacerbación de los actos agresivos en la adolescencia podrían llevarlos al uso de armas blancas y de fuego en situaciones consideradas criminales (Sharp y Smith, citados por Cobo y Tello, 2013).

- Castro y Reta (2013) adicionan, como consecuencias, el comportamiento social inadecuado, abuso de poder, pertenencia a bandas agresivas, conflicto afectivo (miedo/ inseguridad/prepotencia), sumisión ante el más fuerte, trastorno de personalidad, ausencia de empatía, incapacidad para percibir los sentimientos de sus pares, moralidad egocéntrica, irrespeto hacia las demás personas, déficit en su desarrollo moral y eventual desadaptación laboral.

\section{En los sujetos testigos}

Los sujetos testigos se constituyen en los espectadores y espectadoras que guardan silencio cuando presencian episodios de acoso, debido a que se ven inmovilizados por el temor que experimentan ante la posibilidad de convertirse en eventuales víctimas de bullying, o bien, porque son de la opinión de que lo acontecido no les incumbe y que nada de lo que hagan hará la diferencia.

No obstante lo anterior, cabe decir que las repercusiones que estas experiencias tienen en las personas que presencian el acoso son las siguientes:

- Sentimiento de miedo, de culpa, sumisión, pérdida de empatía, desensibilización, insolidaridad e interiorización de conductas antisociales y delictivas como medio para satisfacer necesidades (Oñederra, 2008).

- Conflicto de emociones, ya que por una parte sienten pena por lo que acaece, vergüenza por mantener el silencio y consuelo de que sea otro par y no él o ella quien sufre el acoso (Cobo y Tello, 2013).

- Se sobreagrega el déficit en el desarrollo moral y emocional, un sentimiento de indefensión similar al de la víctima, confusión ante lo que corresponde al éxito social y maltrato y un déficit en la jerarquización de valores introyectados, indiferencia (Castro y Reta, 2013).

En respuesta a lo antes citado, el presente documento muestra los principales resultados obtenidos del grupo de menores de edad participantes en el Proyecto denominado "El impacto del Bullying en el desarrollo integral y aprendizaje de los niños y niñas en edad preescolar y escolar", adscrito al Programa Educación de Calidad del Instituto de Estudios Interdisciplinarios de la Niñez y la Adolescencia (INEINA) (Morales y Villalobos, 2015). 
doi: http://dx.doi.org/10.15359/ree.21-3.2

URL: http://www.una.ac.cr/educare

CORREO: educare@una.cr

\section{Aspectos metodológicos}

La manera como se buscó cumplir con el objetivo coloca este estudio en una investigación de enfoque mixto, en razón de que emplea técnicas cualitativas y cuantitativas que permiten complementar y potenciar la información conseguida. Cada uno desempeña una función específica, la cual permite conocer y comprender un fenómeno social (Hernández, Fernández y Baptista, 2003). El estudio es de tipo exploratorio en tanto la revisión bibliográfica existente en el ámbito nacional no ofrece datos sustantivos en torno al efecto que el acoso escolar tiene en el desarrollo integral y aprendizaje de la víctima, todo lo cual consiente mediante las respuestas brindadas por la población participante, describir y hacer algunas inferencias acerca de la influencia que ejerce en el aprendizaje y desarrollo de una persona menor de edad, la vivencia del acoso escolar.

Los catorce centros educativos públicos (13) y privados (1) colaboradores son de la provincia de Heredia, Costa Rica. La elección de estos se hizo al azar y eventualmente se coordinó con la respectiva dirección, a efecto de obtener el aval de todos los actores participantes en la investigación, a saber: personal docente y administrativo, estudiantes y figuras parentales.

La población contribuyente en este estudio la constituyen 237 estudiantes de preescolar (27.6\%); 286 de III grado (33.4\%) y 334 de VI grado (39\%). Las edades de estos menores de edad corresponden en su mayoría a seis años (preescolar), nueve años (III nivel) y 12 años (VI grado), para un total de 857 estudiantes.

Para recopilar la información se construyó un cuestionario dirigido a los niños y las niñas, con preguntas abiertas y cerradas cuya respuesta es Sí o NO, que tenían por objetivo conocer la percepción de cada estudiante acerca de diversos tópicos concernientes al acoso escolar. La niñez de preescolar fue entrevistada por las investigadoras y colaboradoras, con base en el cuestionario diseñado para tal fin, debido a que no sabían leer ni escribir, destreza que sí tenían los grupos de III y VI grados. Cabe decir que las preguntas se adecuaron a partir de las observaciones derivadas de la aplicación previa del instrumento a un grupo de niños y niñas con características similares a las de la muestra.

Para el análisis de los resultados se elaboraron tablas que complementan datos cuantitativos con los cualitativos. La información cualitativa se visualiza en ellas mediante las categorías emergentes construidas a partir de las respuestas aportadas por el estudiantado y contenidas en tablas tal cual las manifestaron, lo que facilita la comprensión de los hechos, así como la cuantificación en número y porcentaje de las respuestas que corresponden a cada categoría.

A continuación, se hace referencia a datos que evidencian el impacto que desde la perspectiva de los niños y niñas de preescolar, III y VI grados, tiene el acoso escolar en su proceso de desarrollo y aprendizaje. 


\section{Análisis de datos}

Acerca de la cantidad de niños y niñas que manifestaron haber sido acosados (229, $26.7 \%$ ) se tieneque corresponde al $42.4 \%$ de estudiantes de preescolary lll grado respectivamente y a un $15.2 \%$ que cursaban el sexto grado.

Además, se encontró que el 3.4\% del estudiantado de preescolar (8), el 7\% de III grado (20) y el $5.7 \%$ de VI grado (19) reconocieron abiertamente estar acosando a uno de sus pares. Las razones del porqué lo hacen giran en torno a que es para defenderse de otros sujetos acosadores que les molestan y les golpean. No obstante, llama la atención que un niño de preescolar (2.1\%) lo realiza "por diversión" y seis infantes de III y sexto grados (12.8\%) indican que lo hacen para "molestar", o "joder un rato al compañero". Es importante además resaltar que 33 (70.2\%) dicen sentirse mal cuando han agredido a sus iguales y que al 78.7\% (37) les gustaría dejar de hacerlo.

El 46.4\% (398) del estudiantado comentó que observó episodios de acoso hacia uno de sus pares en el centro educativo (33.4\% de preescolar, $41.2 \%$ de III grado y $25.4 \%$ de VI grados).

En relación con el tiempo de ser maltratados, se encontró que el 39.7\% de las personas menores de edad lleva de uno a varios meses de estarlo sufriendo, el 13.1\% manifestó tener dos semanas o más, un $12.2 \%$ dijo que son varios años y un $10 \%$ señaló un año de sufrir maltrato.

Acerca de la cantidad de veces que la población estudiantil es maltratada, se tiene que de una a dos veces al día lo indicó el $40.2 \%$ de las personas; todos los días según el $21 \%$ y una vez a la semana lo señaló el $14.8 \%$ de los niños o niñas. Cabe decir que esta información es consecuente con el planteamiento de Olweus, 1986 y 1991 (citado por Olweus, 1998), quien considera que estamos frente a una situación de acoso e intimidación cuando "un alumno es agredido o se convierte en víctima cuando está expuesto, de forma repetida y durante un tiempo, a acciones negativas que lleva a cabo otro alumno o varios de ellos" (p. 25).

La población participante indica que la persona que les lesiona es un niño, según el $66 \%$ y una niña es quien acosa al $18.8 \%$ de las personas menores.

Acerca de la edad de quien maltrata, cabe decir que el $17.6 \%$ apuntó que la persona que los agrede es más o menos de su edad, mientras que el 15.3\% informó que es mayor que la víctima y según el $8.7 \%$ son personas menores que el niño o niña agredido.

Respecto al $26.7 \%$ de la niñez que dijo estar siendo acosada, solamente el $68.6 \%$ lo reportó a la docente (preescolar y III grado) y a las figuras parentales (VI grado), quienes optaron ante la noticia por hablar, regañar y aconsejar al sujeto acosador principalmente, todo lo cual es coincidente con el enunciado de Educarchile (2009) en cuanto a que las personas que son víctimas del bullying, las más de las veces tienden a no hacer referencia a la experiencia que están enfrentando, ya que les dan mucho miedo las represalias por parte del sujeto acosador o 
doi: http://dx.doi.org/10.15359/ree.21-3.2

URL: http://www.una.ac.cr/educare

CORREO: educare@una.cr

bien creen que de contarlo a alguien, se les percibiría como muy frágiles e incompetentes para hacer frente a la situación por sí, razón por la que recibirán aún más rechazo o aislamiento.

La población estudiantil consultada indica que tanto en el aula como en los recreos u otros lugares que señalaron, la principal agresión que reciben es la física y la verbal, puesto que les golpean, agreden, empujan y ofenden con palabras. Los lugares coinciden con los que Barri (2010) y Ledezma (2015) señalan como aquellos en los que el acoso escolar se presenta con mayor frecuencia, a saber, en el aula, el patio escolar, durante el recreo, la calle, los pasillos, los servicios sanitarios, los vestuarios, los comedores, el transporte escolar, el patio trasero y la cancha de deportes, caracterizados por la debilidad y tolerancia de los actos del estudiantado, ante la ausencia de supervisión por parte del docente responsable.

El principal impacto que ha tenido el acoso en estudiantes que dijeron estarlo sufriendo, es en el área socioemocional, en tanto argumentan sentirse muy mal en general como persona, algunas de las respuestas brindadas por estudiantes de preescolar son: "me siento mal, siempre me hace llorar, yo soy chiquita y la piel me duele", "me siento muy triste", "a veces me siento como muy arrecha, porque ellos me pelean, pellizcan", "me siento con dolor", "me decía venga acá, me agarraba del brazo y no me dejaba ir, me sentí con miedo". Otras respuestas aportadas por estudiantes de III y VI grados tienen que ve con: "me siento mal porque me duele", "una experiencia fea, horrenda", "yo me siento triste", "miedo", "me ha estresado", "furiosa porque me molesta", "me siento mal cuando me lo hacen", "en la forma de pensar o sea psicológicamente", "tengo pensamientos malos y estraños hacia él".

Acerca del impacto que el acoso provoca en el aprendizaje, se tiene que sesenta y siete estudiantes (29.2\%), manifiestan su deseo de no asistir a la escuela debido al acoso que están sufriendo ( $17.5 \%$ de preescolar, $38.1 \%$ de III grado y un $37.1 \%$ de VI grado).

La información anterior se constata con lo que al respecto apuntan Castro y Reta (2013) acerca de que la niñez acosada enfrenta el riesgo de tener dificultades de aprendizaje, discapacidades físicas y sociales, desmotivación por aprender, necesidad de afecto, inmadurez emocional, aprendizaje de conductas agresivas, ausencia de autocontrol e inhabilidad social.

El apartado siguiente, hace referencia a las principales conclusiones derivadas del análisis de la información aportada por los sujetos participantes menores de edad en la investigación.

\section{Conclusiones}

- El $26.7 \%$ del total de estudiantes dijeron ser objeto de acoso. De este porcentaje, el $42.3 \%$ son de preescolar y III grado respectivamente y el $15.3 \%$ cursa el VI grado. Esta información demanda de atención urgente, especialmente si se agrega el dato de que el $3.4 \%$ de los niños y niñas de preescolar, el $7 \%$ de III grado y el $5.7 \%$ de sexto grado, dijo estar acosando 
a algún compañero o compañera y que el $46.4 \%$ de la totalidad de estudiantes alegó haber observado episodios de acoso hacia otro compañero o compañera en el centro educativo (33.4\% de preescolar, $41.2 \%$ de III grado y $25.4 \%$ de VI grado), todo lo cual hace pensar que en los centros educativos participantes, las manifestaciones de violencia que están viviendo los niños y las niñas es tal, que podrían llevarles a una habituación de la conducta al punto de visualizarla como normal e institucionalizarse esta en la cotidianidad.

- La población estudiantil consultada indica que tanto en el aula como en los recreos u otros lugares que señaló, la principal agresión que recibe es la física y la verbal, puesto que les golpean, agreden, empujan y ofenden con palabras. Llama la atención que los principales espacios en los cuales se manifiestan los episodios de violencia son aquellos en los que la persona adulta está o debe estar presente, como es el aula, los recreos, el comedor, los pasillos, lo que a todas luces hace suponer que no está cumpliendo con el rol que le corresponde en materia de protección del estudiantado a su cargo.

- Del $26.7 \%$ de los niños y niñas que dijeron recibir maltrato principalmente por otro par, se podría inferir que el $86.5 \%$ sí está siendo víctima de bullying, ya que el tiempo que la mayoría tiene de vivir esta situación va de semanas a un año, episodios que además se reiteran hasta dos veces en el mismo día. Este dato pone en evidencia el incumplimiento del debido proceso que debe seguirse con base en la normativa establecida por el Ministerio de Educación Pública de Costa Rica, para el abordaje de situaciones de acoso escolar.

- Si bien el $26.7 \%$ de menores de edad están recibiendo acoso, solamente el $68.6 \%$ lo reportó a la docente (preescolar y III grado) y a las figuras parentales (VI grado), quienes optaron ante la noticia por hablar, regañar y aconsejar al sujeto acosador principalmente, según opinión del estudiantado consultado. Muy pocas veces tomaron las medidas que garantizaban la protección del niño o niña, aunadoal hecho de que el 14.6\% de estudiantes manifestó que la persona adulta a la que le contaron no hizo nada para apoyarles. Se adiciona a este dato el que 24 personas víctimas de acoso no dijeron nada por temor a que les dañaran más y al regaño. Nuevamente queda en evidencia el incumplimiento por parte del personal docente en lo que le compete en cuanto a supervisión, abordaje ante cualquier situación de violencia que observe o que le manifiesten o denuncien.

- Integrando el dato de estudiantes que dijeron estar sufriendo bullying, quienes están acosando y quienes lo han observado, el número de personas menores de edad lastimada producto de esta práctica asciende a 674 estudiantes de un total de 857 participantes, es decir, un $78.6 \%$ está sufriendo acoso en el centro educativo. Aunado a lo anterior es importante señalar que para Orpinas y Horne, (2006 citado en Berger y Lisboa, 2009 y ambos citados por Fundación Astoreca, s. f., p. 4) los factores de riesgo que podrían presentarse en la comunidad escolar son: 
doi: http://dx.doi.org/10.15359/ree.21-3.2

URL: http://www.una.ac.cr/educare

CORREO: educare@una.cr

- Espacios sin supervisión de adultos [especialmente en los recreos].

- Normas difusas en la institución

- Normalización de la violencia ... o el trato abusivo como una forma de relacionarse.

- Inconsistencia entre el discurso y el actuar de los adultos [al solicitar]... respeto [entre estudiantes, docentes agresivos y con relaciones entre ellos] inadecuadas (difundir rumores, no considerar la opinión de los otros, agredirse, entre otros.)

- Normativa disciplinaria punitiva.

- Se desprende de la información recopilada de las personas menores de edad que están sufriendo acoso escolar, que lo están actuando con un compañero o compañera y que lo están observando, queel impacto que tieneesta problemática es en elárea socioemocional fundamentalmente. En el aprendizaje, si bien el efecto negativo no está explicitado por ellos y ellas, sí está determinado por el $17.5 \%$ de estudiantes de preescolar, el $38.1 \%$ de III grado y el 37.1 de VI grado, que manifestaron no desear regresar al centro educativo por el acoso. Además, si la población estudiantil se siente mal, triste, enojada, con dolor, temerosa, lastimada, que le afecta en todo, mal consigo misma, emocionalmente dañada y con un concepto desvalorizado de sí misma, a todas luces repercute en la motivación y las condiciones que deben imperar para propiciar el aprendizaje significativo. Al respecto, cabe decir que podrían estar incidiendo otros factores relacionados con la forma de crianza de las familias que no favorecen una comunicación basada en el respecto, la confianza, el apoyo, las manifestaciones afectivas, tiempo de calidad para dedicar a la prole y presencia de un comportamiento transgresor.

\section{Recomendaciones para los centros educativos}

- Realizar un diagnóstico en el centro educativo que determine la prevalencia o no del acoso escolar.

- Capacitar a la comunidad educativa acerca del bullying o acoso escolar en todas sus manifestaciones, síntomas, impacto, formas de prevenirlo y de intervenirlo, de manera que no se asuma como un conflicto de violencia aislado, pues si bien ambos deben eliminarse, los procedimientos son diferentes.

- Crear y poner en práctica en la escuela un programa de prevención y atención del acoso escolar, diseñado con representantes de los actores de la comunidad de aprendizaje y basado para su ejecución en la normativa institucional vigente, para el manejo de estos conflictos, así como con acciones claramente definidas que contengan todos los niveles de intervención. 
- Supervisar, por parte de todo el personal del centro educativo, al estudiantado, especialmente en el aula, recreos, pasillos, servicios sanitarios, el comedor y otros lugares identificados como propicios para actos de violencia y acoso.

- Establecer y cumplir, por parte de todas las instancias, las normas de disciplina y convivencia pacífica dentro del aula y centro educativo, consensuadas con la población estudiantil y las figuras parentales.

- Crear, por parte del centro educativo, una estrecha alianza con las familias, basada en una comunicación empática, abierta, flexible, respetuosa y asertiva.

\section{Referencias}

Arroyave, P. (2012). Factores de vulnerabilidad y riesgo asociados al bullying. Revista CES Psicología, 5(1), 118-125. Recuperado de http://revistas.ces.edu.co/index.php/psicologia/ article/view/2171/1459

Baier, A. C. (1993). Moralism and cruelty: Reflections on Hume and Kant. Ethics, 103(3), 436-457. doi: https://doi.org/10.1086/293520

Barri, F. (2010). SOS BULLYING. Prevenir el acoso escolar y mejorar la convivencia. Madrid: WK Educación.

Beane, A. L. (2006). Bullying. Aulas libres de acoso. Barcelona: Graó.

Blanchard, M. y Muzás, E. (2007). Acoso escolar. Desarrollo, prevención y herramientas de trabajo. Madrid: Narcea.

Castro, A. y Reta, C. (2013). Bullying blando, bullying duro y ciberbullying. Nuevas violencias y consumos culturales. Argentina: Homo Sapiens Ediciones.

Cid, P., Díaz, A., Pérez, M. V., Torruella, M. y Valderrama, M. (2008). Agresión y violencia en la escuela como factor de riesgo del aprendizaje escolar. Ciencia y Enfermería, 14(2), 21-30. doi: https://doi.org/10.4067/s0717-95532008000200004

Cobo, P. y Tello, R. (2013). Bullying: El asecho cotidiano en las escuelas. México: Limusa.

Collell, J. y Escudé, C. (2014). Una aproximación al fenómeno del acoso escolar. En R. Bisquerra (Coord.), Prevención del acoso escolar con educación emocional (pp-15-34). España: Editorial Desclée de Brouwer.

Convivencia Escolar. (2011). Somos comunidad educativa: Hagamos equipo. Una propuesta de intervención integral educativa contra el acoso escolar (bullying). México: Autor. Recuperado de https://www.unicef.org/mexico/spanish/Proyecto Somos comunidad educativa.pdf 
doi: http://dx.doi.org/10.15359/ree.21-3.2

URL: http://www.una.ac.cr/educare

CORREO: educare@una.cr

Educarchile (2009). Bullying: La cultura del silencio. Recuperado de http://www.educarchile.cl/ ech/pro/app/detalle?|D=194864\&es=205358

Florian, K. (2003). Abuso a los animales y violencia humana. Recuperado de http://www.gevha. com/analisis/articulos/59-abuso-a-los-animales-y-violencia-humana

Fuensanta, C. (2012). Bullying a través de las TIC. Revista Sapiens Reserch, 2(2), 24-29. Universidad de Murcia España. Recuperado de http://sapiensresearch.org/boletin-cientifico

Fundación Astoreca (s. f.). Protocolo de acción ante acoso escolar. Recuperado de http://www. astoreca.cl/wp-content/uploads/2015/colegios/astoreca-protocolo-acoso-escolar.pdf

Hernández S. R., Fernández C., C. y Baptista, L. P. (2003). Metodología de la investigación (2a ed.) México: McGraw-Hill Interamericana Editores.

Ledezma, A. M. (2015). ¿Cómo afecta el bullying en el rendimiento académico de los alumnos de $7^{\text {er }}$ grado de la secundaria en la escuela "Prof. Sergio Montalvo Garza" de Santiago? (Tesis de maestro). Instituto para el Fomento Científico de Monterrey. Monterrey, México.

Ministerio de Educación Pública. (2012). Protocolo específico para el acoso, matonismo o bullying y el ciberbullying en los centros educativos de primaria. San José, Costa Rica: Autor. Recuperado de http://www.franco.ed.cr/wp-content/uploads/2014/07/PROTOCOLODEL-MEP-CONTRA-BULLYING-MATONISMO-O-CIBERBULLIYNG.pdf

Morales, M. E. y Villalobos, C. M. (2015). El impacto de bullying en el desarrollo integral y apredizaje de los niños y niñas en edad preescolar y escolar, Informe de investigación (Código 0158-11). Universidad Nacional. Recuperado de https://drive.google.com/file/d/OBywhAHdDzjuoY UJGZOU5WG1JbHNsTDNCdEFSdkg0V3NjVVhn/view

Narváez, V.y Salazar, O. F. (2012). Bullying, matoneo, intimidación o acosos escolar. Carta de la Salud, 200, 1-4. Recuperado de http://herazocindy.blogspot.com/2016/10/bullying-pdf.html

Olweus, D. (1998). Conductas de acoso y amenaza entre escolares. Madrid: Ediciones Morata.

Oñederra, J. A. (2008). Bullying: Concepto, causas, consecuencias, teorías yestudios epidemiológicos (XXVII Cursos de Verano EHU-UPV, diapositiva 20). Donostia, San Sebastián Recuperado de http://www.sc.ehu.es/ptwgalam/meriales\%20docentes\%20curso\%20verano\%20 2008/1.\%20Bullying\%20aproximacion\%20al\%20fenomeno\%200nederra.pdf

Pinheiro, P. S. (2006). Informe mundial sobre la violencia contra los niños y niñas. Ginebra: Naciones Unidas. Recuperado de https://www.unicef.org/lac/Informe Mundial Sobre Violencia 1(1).pdf

Rojas, M. L. (2 de abril de 2005). Los estragos del acoso escolar. El país. Opinión. Recuperado de http://elpais.com/diario/2005/04/02/opinion/1112392807 850215.html 